\title{
Depth matching with visible diplopic images: Stereopsis or vernier alignment
}

\author{
S. KREKLING \\ Institute of Psychology, NLHT, University of Trondheim, N-rooo Trondheim, Norway
}

\begin{abstract}
In order to prevent subjects from actually performing a judgment of vernier alignment between the double images rather than matching stereoscopic depth of the test objects, various precautions have previously been taken, e.g., using inexperienced subjects who were ignorant of the experimental situation and possible matching criteria. In the experiment reported here, a subject was given training in observing double images and the matching problems were also discussed. The subject was then instructed to perform stereoscopic depth judgments. The comparison between these data and data based on vernier alignment judgments under similar conditions showed that knowledge about the experimental situation and the vernier alignment criterion did not interfere with the subject's task of matching the stereoscopic depth between visible double images.
\end{abstract}

Stereopsis is commonly experienced with fused monocular half images. In earlier works, it was asserted that fusion of the half images was a necessary condition for the stereoscopic depth impression (Hillebrand, 1929; Matsuda, 1930/31; Nagel, 1861; Trendelenburg \& Drescher, 1926). Recent experiments (Blakemore, 1970; Mitchell, 1966, 1969; Mitchell \& O'Hagan, 1972; Ogle, 1952, 1953; Sachsenweger, 1955; Westheimer \& Tanzman, 1956) show that stereoscopic localization is possible when double images are seen.

Under natural viewing conditions, the subject might base his reports on estimation of the lateral distance between diplopic images (Lie, 1965). Under haploscopic viewing conditions, the subject's response might be based on nonius or vernier alignment impressions (Blakemore, 1970) between half images of the reference and the comparison line. This would actually reduce the task to a simple recognition of nonius misalignment. Various precautions have been taken to prevent this, e.g., using inexperienced subjects who were ignorant about the experimental situation.

In the present experiment, the subject was told how the experiment worked; training in observing double images was given, and the matching problems were discussed. Data on stereoscopic depth and vernier alignment were gathered under similar experimental conditions for comparison.

\section{METHOD}

To give the impression that the test lines ( $\mathrm{R}$ and $\mathrm{Co}$ ) appeared in stereoscopic depth, a mirror (50:50 transmission) haploscope was applied. The two half images of the reference line $(\mathrm{R})$ appeared

This project was supported by the Norwegian Research Council for Science and the Humanities (B.65.01-9). The author is indebted to T. Haug for assistance.
A.
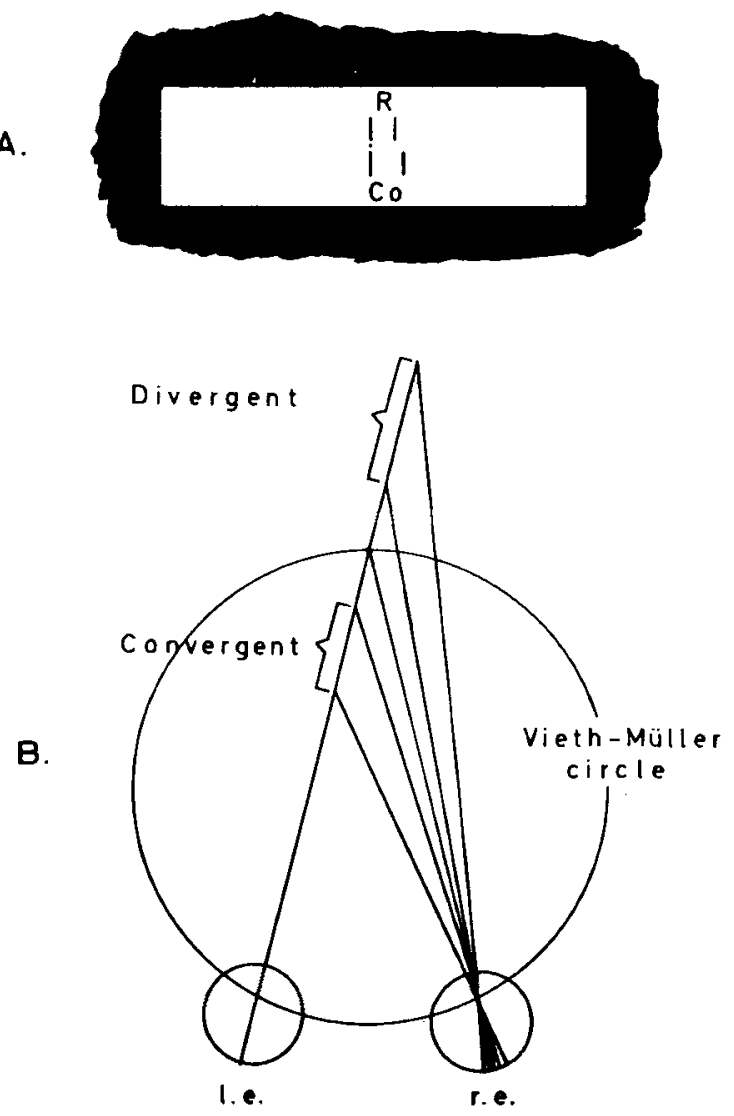

Figure 1. (A) Visual appearance of the stimulus display. (B) Divergent and convergent disparities with reference to the Vieth-Mueller circle.

above the fixation point, and those of the comparison line (Co) below, as shown in Figure $1 \mathrm{~A}$. The half images directly above and below the tixation point projected to the left eye, and were fixed in the position shown. The upper half image shown to the right in the tigurc wals adjusted by the experimenter, and could be presented alternatively to the right and left side of the fixation point to 
introduce divergent and convergent disparity (Figure 1B), respectively. The half image of $\mathrm{Co}$, presented to the right eye (lower right image in Figure 1A), could be adjusted by the subject.

To produce the half in ages of the test lines, opaque lines $(3 \times 30 \mathrm{~min}$ arc) etched on glass plates were inserted in holders on the arms of the haploscope. The test lines were seen against a bright homogeneous background (ca. $40 \mathrm{~mL}$ ) produced by transilluminating opal Perspex sheets. Fixation marks were seen through the 50:50 transmission mirrors. A dental impression mouth-bite was also provided. To prevent disjunctive eye movements, the test fields were exposed for $160 \mathrm{msec}$ (Rashbass \& Westheimer, 1961) by electronically controlled solenoid shutters. The angular disparity of $\mathrm{R}$ and Cocould be changed by adjusting the lateral positions of the glass plates on which the test lines were etched. As the disparity was changed, the stereoscopic impression of relative depth also changed. When the disparity was increased sufficiently, the fused images broke into four visible half images or double images (Figure 1A). In the first experiment, the subject's task was to set the visible double images of the comparison and reference line so that they would appear to lie in the same stereoscopic depth for a series of disparity settings of $\mathrm{R}$. Hence, stereoscopic threshold data were obtained within the "qualitative stereopsis" range (Ogle, 1952). The reference line was preset by the experimenter at different magnitudes of convergent and divergent horizontal disparity. Applying the method of adjustment, the subject adjusted the disparity of the comparison by running a stepper motor which operated a micrometer unit carrying one of Co's half images. For each disparity condition. 30 observations were taken, and the standard deviation (SD) of these provided the stereoscopic threshold data.

A second experiment was performed in order to compare stercoscopic depth settings and vernier alignment adjustments. One half image of both $\mathrm{R}$ and $\mathrm{Co}$ was occluded. The subject was asked to tixate the fixation marks and adjust the lower half image so that it was seen in alignment with the upper half image. This was done for a series of retinal eccentricities on both sides of the foveal center. Otherwise, the experimental conditions were unchanged, and the standard deviation of 30 settings provided the vernier alignment threshold data.

\section{RESULTS AND DISCUSSION}

The results are shown in Figure 2. Log SD of the subject's settings have been plotted against retinal eccentricity and disparity for vernier and depth data, respectively. The scales on the left and the right ordinate axis are identical. Log stereoscopic threshold (broken line and triangles) increased roughly linearly with an increase in convergent and divergent disparity. This agrees fairly well with previous work (Blakemore, 1970; Ogle, 1953). Double images were permanently observed at about $20 \mathrm{~min}$ arc disparity, and the stereothreshold then slightly exceeded 1 min arc. When $R$ was presented at $40 \mathrm{~min}$ arc divergent disparity and $35 \mathrm{~min}$ arc convergent disparity, the subjects' matchings yielded thresholds of $3 \mathrm{~min}$ arc and $5 \mathrm{~min}$ arc, respectively. For still greater disparities of $\mathrm{R}$, the subject reported loss of stereopsis and felt unable to make a meaningful stereoscopic match between the double images of $R$ and $\mathrm{Co}_{0}$. The relationship between the vernier alignment threshold and retinal eccentricity (unbroken line and circles) seem to agree with Jones and Higgins (1947) and Millodot (1966). The

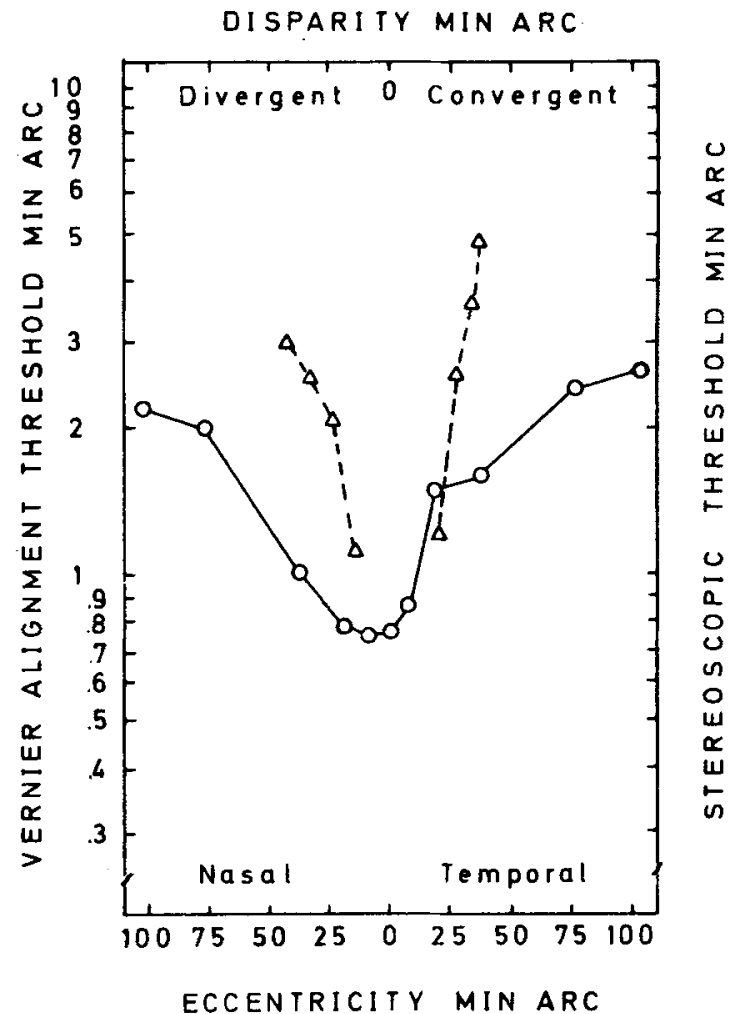

Figure 2. The circles represent data for vernier alignments, and triangles represent data for depth settings. Vernier data were plotted against the left ordinate and the abscissa at the bottom, and stereoscopic data were plotted against the right ordinate and abscissa at the top. The stereoscopic threshold is shown only for disparities yielding visible double images. Zero eccentricity refers to center of fovea and zero disparity refers to the Vieth-Mueller circle.

minimum threshold, however, is somewhat high, which might be due partly to the vertical distance (10 min arc) between the two lines.

Figure 1B shows how divergent and convergent disparate objects project to the nasal and temporal hemiretina, respectively. In order to compare vernier and stereoscopic data, this must be taken into account. The top and the bottom abscissas in Figure 2 have identical scales, and have been arranged to provide for direct comparison between the two sets of data. As the left-eye half image was preset at a fixed position (Figure 1A) throughout the experiment, an increase in disparity could be produced only by increasing the eccentricity (lateral angle) of the adjustable half image. To present, e.g., a $25 \mathrm{~min}$ arc convergent disparity of $R$, the experimenter adjusted one half image of $R$ to a 25 min arc temporal eccentric position. As can be seen from the figure, the stereoscopic threshold was about $2 \mathrm{~min}$ arc at 25 min arc convergent disparity, while the vernier alignment threshold at $25 \mathrm{~min}$ arc temporal eccentricity was about $1 \frac{1 / 2}{\mathrm{~min}}$ arc. Hence, the two 
thresholds can be compared with reference to the retinal areas involved.

It is evident from Figure 2 that the slope of the increase in stereoscopic threshold is quite different from that of the vernier threshold. If the stereoscopic threshold had been measured at, e.g., $1 \mathrm{deg}$ arc peripheral angle or more, the difference between the two sets of data would have been even more conspicuous. While the stereoscopic data most likely reflect properties of the spatial distribution of neural depth-specific units (Blakemore, 1970; Joshua \& Bishop, 1970), the vernier alignment data probably reflect mechanisms altogether different (Matin, 1972).

Knowledge of two possible matching criteria; stereopsis and vernier alignment, did not rule out the possibility that the subject was able to disregard one attribute while attending to the other when instructed to do so. Hence, instead of using inexperienced subjects who are naive about the experimental situation and the possible matching criterions, it might make more sense to train the subject and give explicit instructions about the relevant criterion as well as the subjective attribute in question.

\section{REFERENCES}

Blakemore, C. The range and scope of binocular depth discrimination in man. Joumal of Physiology, 1970, 211, 599-622.

HILlEBRAND, F. Lehre von den Gesichtsemptindungen auf Grund hintcrlassener Aufzeichnungen. Wien: Springer, 1929.

Jones, L. A., \& Higgins, G. C. Photographic granularity and graininess. Journal of the Optical Society of America, $1947,37,217-263$.
Joshua, D. E., \& Bishop, P. O. Binocular single vision and depth discrimination. Receptive tield disparities for central and peripheral vision and binocular interastion of peripheral single units in cat striate cortex. Experimental Brain Research, $1970,10,389-416$.

lak. I. Compergence as a cue to perceived size and distance. Soandimarian Jommal of Psychology. 1965, 6, 109-116.

Matin. L. Eye movenients and perceived visual direction. In D. Jameson and L. M. Hurvich (Eds.), Handbook of sensory physiology (Vol. VII/4) Visual psychophysics. New York: Springer, 1972.

Matsuda. A. Untersuchungen zur optischen Raumwahrnehmung. Zeitschriti für Sinnesphysiologie, 1930/31, 61, 225-246.

Millodot, M. Foveal and extra-foveal acuity with and without stabilized retinal images. British Journal of Physiological Optics, 1966, 23, 75-106.

Mitchell, D. E. Retinal disparity and diplopia. Vision Research, 1966, 6, 441-451.

Mitchell. D. E. Qualitative depth localization with diplopic inages of dissinilar shape. Vision Research, 1969, 9. 911.914.

Mitchell. D. E., \& O'Hagan, S. Accuracy of stereoscopic localization of small line segments that differ in size or oricntation for the wo eyes. Vision Keseurch, 1972, 12, 437.454.

Nagit. A. Das Sohen mit zwei Augen und die Lehre von den identischen Netzhautstellen. Leipzig: Winter, 1861.

OGLE, K. N. Disparity limits of stereopsis. Archives of Ophthalmology, 1952, 48, 50-60.

Ogle, K. N. Precision and validity of stereoscopic depth perception from double images. Journal of the Optical Society of America, 1953, 43, 906-913.

Rashbass, C.. \& Westheimer, G. Disjunctive eye movements. Journal of Physiology, 1961, 169, 339-360.

SACHSENWEgER, R. Untersuchungen über das Verhältnis des stereoscopischen Sehens zu den Panumschen Arealen. Deutsche ophtalmologische Gesellschaft. Bericht uber der 59. Zusammen kuntt, 1959, 296-299.

Trendelenburg, W., \& Drescher, K. Ueber die Grenzen der beidaugigen Tiefenwahrnehmung und Doppelbilderwahrnehmung. Zeitschrift für Biologie, 1926, 84, 427-435.

Westheimer, G., \& Tanzman, I. J. Qualitative depth localization with diplopic images. Journal of the Optical Society of America. $1956,46,116-117$.

(Received for publication January 21, 1974; revision received March $18,1974$. 